\title{
ANTIOXIDANT ACTIVITIES OF SUPERCRITICAL AND CONVENTIONAL EXTRACTS OF CLOVE (Eugenia caryophyllus)
}

\author{
Amanda G. A. SÁ1, Sibele R. R. COMIM², Sandra R. S. FERREIRA² \\ ${ }^{1}$ Universidade Federal de Santa Catarina, Departamento de Engenharia Química e Engenharia de \\ Alimentos \\ 2 Universidade Federal de Santa Catarina, Departamento de Engenharia Química \\ E-mail: amandaa_almeidaa@hotmail.com
}

\begin{abstract}
Clove is a plant that presents antimicrobial, antioxidant and anesthetic properties. The objectives were to evaluate extraction yield and antioxidant activity of clove bud extract. Extraction was performed using supercritical fluid extraction (SFE) with $\mathrm{CO}_{2}$, hydro-distillation (HD) and ultrasound extraction (UE). Extract yield reached values of $22 \pm 1 \%$ (w/w) for UE with ethanol, $13 \pm 2 \%$ (w/w) for UE with water, $12.5 \pm 0.5 \%(\mathrm{w} / \mathrm{w})$ for SFE and $3.6 \pm 0.6 \%(\mathrm{w} / \mathrm{w})$ for HD. The antioxidant activity of extracts was evaluated by $\mathrm{DPPH}$ and best results of $\mathrm{EC}_{50}$ were obtained for UE extracts using ethanol $(26 \mu \mathrm{g} / \mathrm{mL})$ and $\mathrm{HD}(27 \mu \mathrm{g} / \mathrm{mL})$. The total phenolic content was measured by Folin Ciocalteau method and the best result was obtained for SFE $(448 \pm 38 \mathrm{mg} \mathrm{GAE} / \mathrm{g})$. The best result for the method of bleaching system $\beta$ carotene/linoleic acid was achieved for the clove extract obtained by SFE $(94 \pm 4 \%)$. SFE extracts presented lower yields compared to UE extracts, but presented good results of antioxidant activity.
\end{abstract}

\section{INTRODUCTION}

The food, cosmetics and pharmaceuticals industries are benefited by the use of essential oils because of the aromatic compounds with therapeutic properties and protection against oxidation processes (Andrade et al., 2012).

Brazil is a major producer of spices and herbs, and its main products are pepper, clove, cinnamon, ginger, mint, eucalyptus and chamomile (Oliveira et al. 2009).

Clove (Eugenia caryophyllus) is a plant widely used for various applications. The literature presents publications attributing biological activities to the essential oil of clove, such as antimicrobial, antioxidant and anesthetic (Scherer et al., 2009).

Demand for natural antioxidants has been increased due to consumer concerns about the safety of synthetic antioxidants. Among the groups of components with antioxidant properties against radical reactions are the phenolic compounds, particularly flavonoids, which have shown important antioxidant activity based on their structural characteristics, such as number and position of phenolic hydroxyls and other groups. Additionally, antioxidant compounds are used 
in oily food products, to prevent or reduce the oxidative rancidity, and also play an important role in preventing or slowing the progress of degenerative diseases (Benneli et al., 2010).

Therefore, the aim of the present work was to investigate the extraction of clove (Eugenia caryophyllus) oil by supercritical fluid extraction (SFE) with $\mathrm{CO}_{2}$, by ultrasound extractions (UE) with different solvents and by hydro-distillation (HD). The results were compared in terms of process yield and antioxidant activity by DPPH, total phenolic content (Folin Ciocalteau) and $\beta$ carotene bleaching methods. The kinetic and the mathematical modeling of the SFE were also studied.

\section{MATERIALS AND METHODS}

\subsection{Raw Material and Sample Preparation}

The clove (button) used to perform the extraction was purchased at a health food store, located in Itajaí/SC, Brazil. The material was ground in a knife mill (De Leo, Porto Alegre/RS, Brazil) and characterized by size classification in a vertical vibratory sieve shaker (Bertel Metalurgic Ind. Ltda., Caieiras/SP, Brazil). For the experiments, the fraction of material used was between sieves size $-20 /+65$ mesh. The sample was stored at $255,15 \mathrm{~K}$ in a domestic refrigerator (Freezer 250, Brastemp, São Paulo/SP, Brazil) until the extractions were performed.

\subsection{Supercritical Fluid Extraction (SFE)}

The SFE of clove was performed in a dynamic extraction unit with $\mathrm{CO}_{2}$ as solvent, $99.9 \%$ pure (White Martins, Brazil). The extraction procedure was described by Wenqiang et al. (2007). It was performed in a packed bed of $15 \mathrm{~g}$ of milled material at 100 bar and $50^{\circ} \mathrm{C}$ with a minimum mass flow rate of $\mathrm{CO}_{2}$ of $0.2 \mathrm{~kg} / \mathrm{h}$ for $90 \mathrm{~min}$. The extract was collected in amber flasks and weighted in an analytical balance (AY220, Shimadzu do Brasil Ltda., São Paulo/SP, Brazil). Figure 1 presents the supercritical extraction equipment.

The yield results of SFE assay was obtained by the mean value of the duplicated experiments considering the ratio between mass of extracted oil and mass of raw material. The yield results were compared with data from the different extraction techniques (Section 2.3).

\subsection{Low Pressure Extraction (LPE)}

Ultrasound extraction (UE): The extractions were run according to Benneli et al. (2010). It was used $7 \mathrm{~g}$ of clove sample and $210 \mathrm{~mL}$ of solvent, placed inside an amber flask. The extraction time was $1 \mathrm{~h}$, conducted at room temperature and performed in duplicate. The equipment used was an ultrasonic cleaner bath (Unique Ultracleaner, USC-700), which operates in a frequency of $55 \mathrm{kHz}$ and potency of $220 \mathrm{~V}$. The UE was performed with ethanol (EtOH) and distillated water (WT), with polarity of 5.2 and 9.0, respectively (Benneli et al., 2010). 


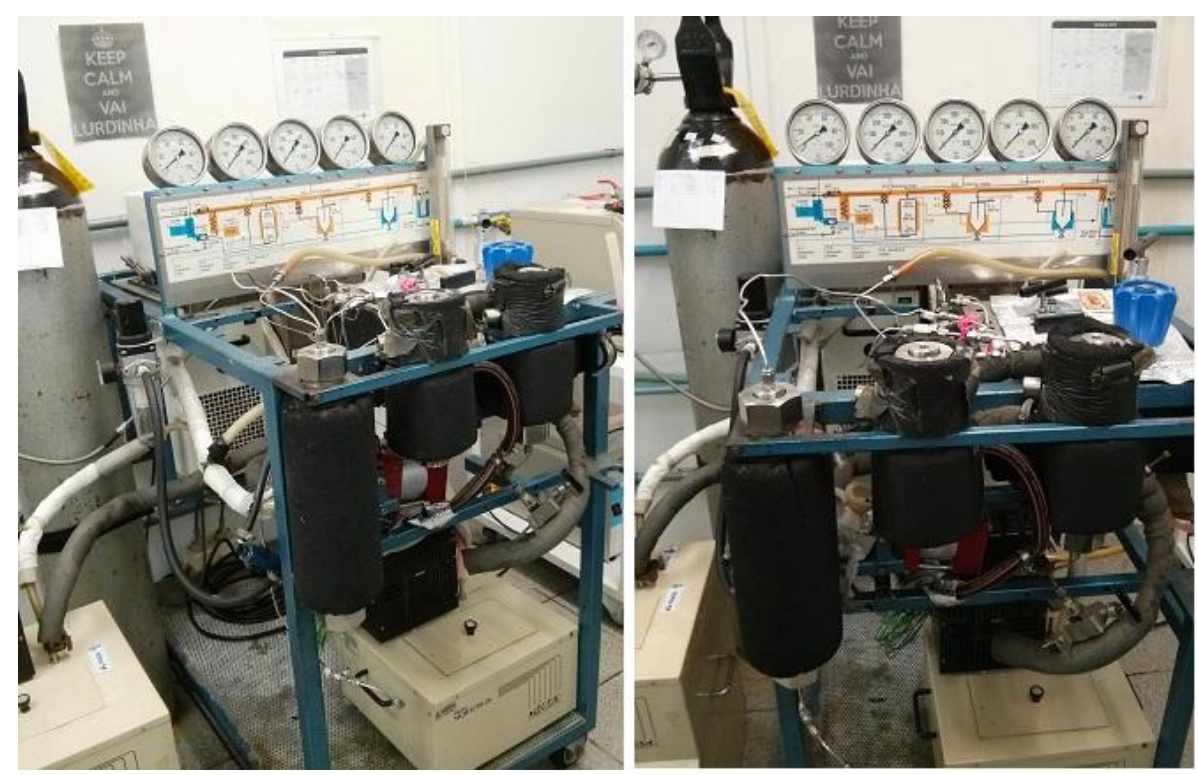

Figure 1 - Supercritical extraction equipment.

Hydro-distillation (HD): The HD extraction was carried out with $50 \mathrm{~g}$ of sample and 700 $\mathrm{mL}$ of distillated water placed inside a modified Clevenger apparatus for $6 \mathrm{~h}$ at water boiling point.

Extracts treatment and solvent elimination: The resulting mixtures from each technique with different solvents, were separated by using reduced pressure to evaporate the solvents in a rotary evaporator (Mod. 550 e 802, Fisatom, São Paulo/SP, Brazil) obtaining the extracts. The global yield for each low pressure extraction (UE and HD) was obtained by the mean value from the duplicate experiments considering the ratio between mass of extracted oil and mass of raw material used.

\subsection{Mathematical Modeling}

The overall extraction curve (OEC) for the clove supercritical extraction was obtained by the extraction yield (as accumulated mass) versus extraction time. In the kinetic evaluation the Martinez et al. (2003) model was adjusted to the extraction curve.

The OEC may be represented by three sections: the constant extraction rate period (CER), the falling extraction rate period (FER) and the diffusive controlled period (DCP) (Ferreira and Meireles, 2002).

The software Mass Transfer, developed by Correia et al. (2006) and described by Kitzberger et al. (2009) was used to implement the model. The logistic model by Martinez et al. (2003) is based on the mass balance of the extraction bed and neglects the accumulation and dispersion in the fluid phase because these phenomena have no significant influence on the process when compared to convection effect. 


\section{9 a 22 de outubro de 2014 \\ Florianópolis/SC}

\subsection{AntioxidantActivity}

The antioxidant activity was performed for all clove extracts obtained by SFE and by LPE. The results were compared with a synthetic compound with antioxidant activity, BHT (butylated hydroxyl toluene).

Free radical scavenging activity (DPPH): The free radical scavenging activity of the clove extracts was evaluated using 1,1-diphenyl-2-picrylhydrazil (DPPH) radical scavenger method. Briefly, the clove extract was mixed with a $0.3 \mathrm{mmol} / \mathrm{L} \mathrm{DPPH}$ ethanol solution to give final concentrations of 5, 10, 25, 50, 125, 250 and $500 \mathrm{mg} / \mathrm{mL}$ of DPPH solution. After 30 min at room temperature, the absorbance values were measured at $517 \mathrm{~nm}$ and converted into percentage of antioxidant activity (\%AA). DPPH is a free radical, stable at room temperature, which produces a violet solution in ethanol. In presence of antioxidant compounds the DPPH is reduced producing a non-colored solution. This activity was also expressed as the effective concentration at $50 \%$ $\left(\mathrm{EC}_{50}\right)$, the concentration of the solution required to give a $50 \%$ decrease in the absorbance of the test solution compared to a blank solution (Mensor et al., 2001). The result data for DPPH assays were obtained considering the mean value of triplicate assays.

Total phenolic content (TPC): The TPC was determined for each extract sample according to the Folin Ciocalteau method (Singleton, 1965; Peschel et al., 2006). Briefly, the reaction mixture was composed by $0.1 \mathrm{~mL}$ of extract $(1.67 \mathrm{~g} / \mathrm{L}), 0.5 \mathrm{~mL}$ of Folin Ciocalteau reagent (a mixture of phosphomolybdate and phosphotungstate) and $1.5 \mathrm{~mL}$ of $20 \%$ sodium carbonate, placed in amber flasks. The flasks were agitated, held for $2 \mathrm{~h}$ and the absorbance was measured at $765 \mathrm{~nm}$. The TPC was calculated according to a standard curve, prepared previously with gallic acid. The results (mean value of the triplicate assays) were expressed as milligrams of gallic acid equivalent (GAE) per gram of the extract (mg GAE/g).

$\beta$-carotene bleaching method: A model system made of $\beta$-carotene and linoleic acid undergoes a rapid discoloration in the absence of an antioxidant. The free linoleic acid radical is formed upon a hydrogen reduction by the $\beta$-carotene molecules, changing its color. The $\beta$ carotene bleaching rate was determined by the differencein absorbance $(470 \mathrm{~nm})$ values at $2 \mathrm{~h}$. The antioxidant activity from the $\beta$-carotene/linoleic acid system was carried out according to the method described by Matthäus (2002) and Kang et al. (2006). Briefly, $40 \mathrm{mg}$ of linoleic acid and $400 \mathrm{mg}$ of Tween 20 were transferred into a flask and $1 \mathrm{~mL}$ of chloroform was added. Chloroform was removed by rotary evaporation at $40^{\circ} \mathrm{C}$. Then $100 \mathrm{~mL}$ of distilled water was slowly added and vigorously agitated to form a stable emulsion. An aliquot of $5 \mathrm{~mL}$ of this emulsion was added with $0.2 \mathrm{~mL}$ of ethanolic clove extract solution $(1.67 \mathrm{~g} / \mathrm{L})$ and the absorbance was immediately measured at $470 \mathrm{~nm}$ against a blank consisting of the emulsion without $\beta$-carotene. The tubes were placed in a water bath at $50^{\circ} \mathrm{C}$ and the absorbance was measured every $30 \mathrm{~min}$ up to $120 \mathrm{~min}$. The absorbance values (mean of the triplicate experiments) were converted into percentage of antioxidant activity (\%AA). 


\subsection{Statistical Analysis}

The global yield and antioxidant activity results were statistically evaluated by a one-way analysis of variance (ANOVA), using the Software Microsoft Excel 2007 in order to detect significant differences between values in clove oil extractions by SFE and LPE, and among the percentage of antioxidant activity. The significant differences $(p<0.05)$ were analyzed by Tukey's test.

\section{RESULTS AND DISCUSSION}

\subsection{Global Yield of SFE and LPE}

The results for extraction yield obtained by UE with different solvents and HD are presented in Table 1, which compares the values for global yield obtained by SFE.

Table 1 - Global yield of clove extracts obtained by LPE and SFE

\begin{tabular}{ccc}
\hline Extraction $^{(1)}$ & Solvent & Global yield $(\%, \mathbf{w} / \mathbf{w})^{(2)}$ \\
\hline $\mathbf{U E}$ & Ethanol & $22^{\mathrm{a}} \pm 1$ \\
$\mathbf{U E}$ & Water & $13^{\mathrm{b}} \pm 2$ \\
$\mathbf{H D}$ & Water & $3.6^{\mathrm{c}} \pm 0.6$ \\
SFE $\left(\mathbf{5 0} \mathbf{0}^{\circ} \mathbf{C} \mathbf{1 0 0}\right.$ bar $)$ & $\mathrm{CO}_{2}$ & $12.5^{\mathrm{b}} \pm 0.5$ \\
\hline
\end{tabular}

(1) SFE: supercritical fluid extraction, HD: hydro distillation, UE: ultrasound extraction.

(2) Same letters indicate no significant difference at level of $5 \%(\mathrm{p}<0.05)$.

According to Table 1, the UE (Ethanol) provided highest global yield value of $22 \pm 1 \%$ (w/w). The UE (Water) and SFE are not statistically different at 5\% level of significance (p < $0.05)$. The HD had the lowest global yield value $(3.6 \pm 0.6 \%(\mathrm{w} / \mathrm{w}))$, which indicates that high temperature applied in the extraction and the long time destroyed volatile compounds, decreasing the global yield.

Martinez et al. (2007) studied supercritical extraction of clove at a pressure of $100 \mathrm{bar}$ and temperature of $35^{\circ} \mathrm{C}$ and obtained yield of $13.5 \%(\mathrm{w} / \mathrm{w})$, a similar result to that obtained in this work.

\subsection{Mathematical Modeling}

The experimental and the modeled OEC for clove extract are presented in Figure 2. According to the kinetics assays from the SFE conducted at $100 \mathrm{bar}, 50^{\circ} \mathrm{C}$ and $0.2 \mathrm{~kg} \mathrm{CO} / \mathrm{h}$, the constant extraction rate (CER) period occurs between 0 and $50 \mathrm{~min}$, the falling extraction rate (FER) period seems to begin after $50 \mathrm{~min}$ (between 50 and $60 \mathrm{~min}$ ) while the diffusive controlled period (DCP) started after $60 \mathrm{~min}$. The adjustable parameter $b$ and mean square errors (MSE) obtained by the Martinez et al. (2003) model is 0.08 and 0.002 respectively. 


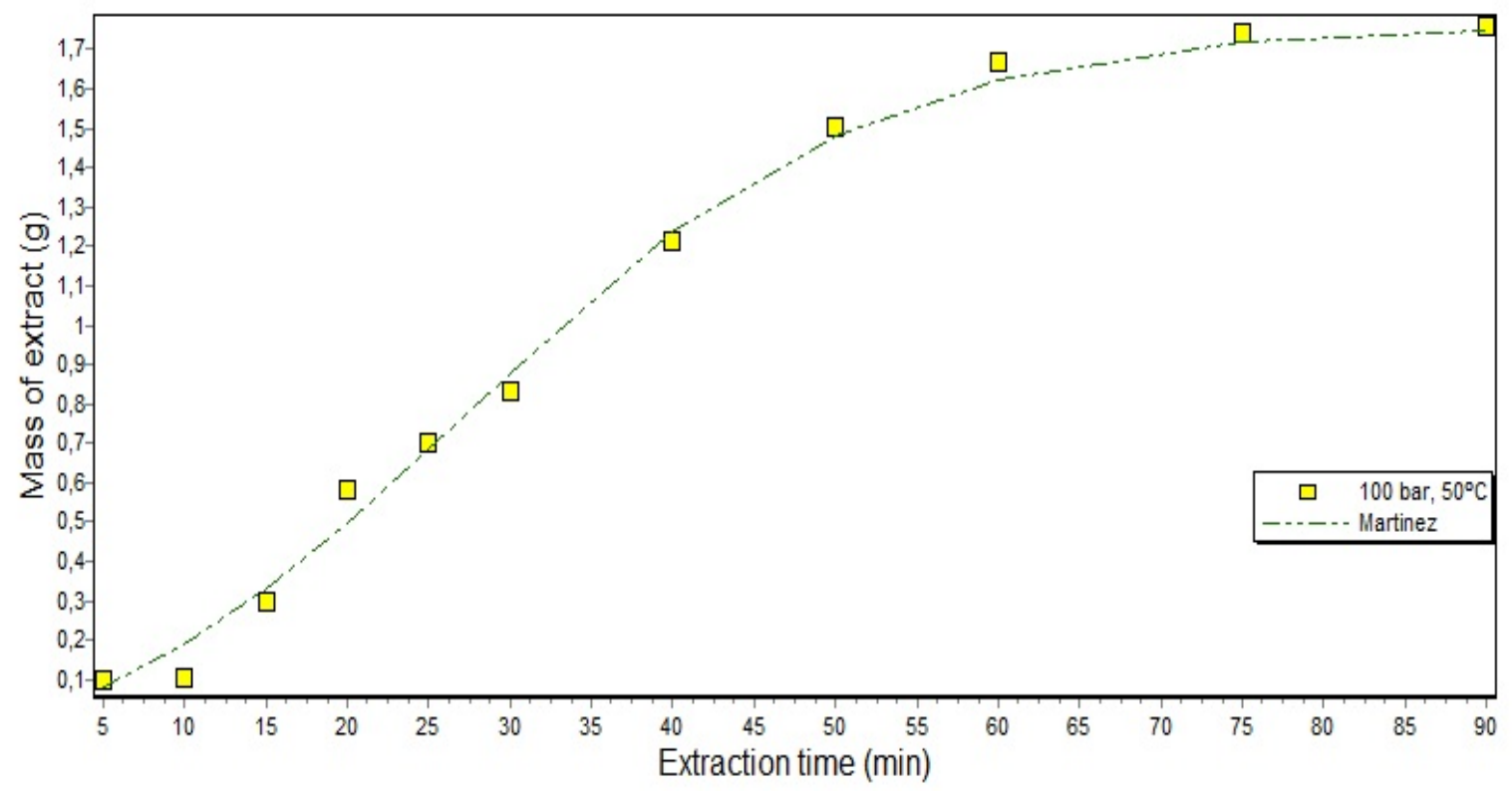

Figure 2 - Experimental and modeled curve from SFE of clove extract at $100 \mathrm{bar}, 50^{\circ} \mathrm{C}$ and $0.2 \mathrm{~kg} / \mathrm{f}$ of $\mathrm{CO}_{2}$.

The Martinez et al. (2003) model presents a good fit to the clove extraction curve because the mean square errors value is negligible.

\subsection{Antioxidant Activity}

Antioxidant activity results for DPPH, TCP (Folin Ciocalteau) and $\beta$-carotene/linoleic acid analysis for clove extracts obtained from different extraction methods (SFE and LPE) compared to BHT are presented in Table 2.

The best $\mathrm{EC}_{50}$ results (determined by DPPH method) were obtained by UE (Ethanol) and HD extraction, although these results are not statistically different at 5\% level of significance $(\mathrm{p}<0,05)$. According to Table 2, the values of antioxidant activity (\%AA) for clove extracts were higher than for the synthetic antioxidant $\mathrm{BHT}$ and the $\mathrm{EC}_{50}$ results for $\mathrm{BHT}$ were higher, which shows that the clove extracts have great potential antioxidant.

The best TPC result was obtained for SFE (448 $\pm 38 \mathrm{mg} \mathrm{GAE} / \mathrm{g})$. The literature shows $50^{\circ} \mathrm{C}$ as the optimum temperature for phenolic compounds extraction from vegetable matrixes (Benneli et al., 2010). Table 2 shows that the total phenolic content of clove extracts were higher than the synthetic antioxidant BHT, which shows that it was possible to extract phenolics compounds effectively.

According to Table 2, values for the antioxidant activity by $\beta$-carotene bleaching method show that SFE obtained at 100 bar and $50^{\circ} \mathrm{C}(94 \pm 4 \%)$ are not statistically different at level of $5 \%$ from BHT results $(99 \pm 7 \%)$. The supercritical technology proved to be very effective in the extraction of phenolic compounds, this result suggests that heating the solution for the test of 
antioxidant activity for the temperature during the extraction process (around $50^{\circ} \mathrm{C}$ ), does not cause the decrease of antioxidant activity, which is useful in food processing.

Table 2 - Antioxidant activity for clove extracts from different methods and BHT

\begin{tabular}{|c|c|c|c|c|c|}
\hline Extraction $^{(1)}$ & Solvent & $\% \mathbf{A A}_{\max }{ }^{(2)}$ & $E C_{50}(\mu \mathrm{g} / \mathrm{mL})^{(3)}$ & TPC (mg GAE/g) ${ }^{(4)}$ & $\% \mathbf{A A}^{(5)}$ \\
\hline UE & Ethanol & $94^{\mathrm{a}}$ & $26^{\mathrm{c}}$ & $397^{\mathrm{f}} \pm 9$ & $72^{j} \pm 1$ \\
\hline UE & Water & $97^{\mathrm{b}}$ & $79^{d}$ & $90^{\mathrm{g}} \pm 1$ & $9^{\mathrm{k}} \pm 1$ \\
\hline HD & Water & $94^{\mathrm{a}}$ & $27^{\mathrm{c}}$ & $402^{\mathrm{f}} \pm 10$ & $80^{\mathrm{j}} \pm 5$ \\
\hline SFE & $\mathrm{CO}_{2}$ & $91^{\mathrm{a}}$ & $33^{\mathrm{c}}$ & $448^{\mathrm{h}} \pm 38$ & $94^{1} \pm 4$ \\
\hline BHT & - & $90^{\mathrm{a}}$ & $261^{\mathrm{e}}$ & $268^{i} \pm 13$ & $99^{1} \pm 7$ \\
\hline
\end{tabular}

* Same letters indicate no significant difference at level of $5 \%(\mathrm{p}<0.05)$.

(1) SFE: supercritical fluid extraction, HD: hydro distillation, UE: ultrasound extraction.

(2) Antioxidant activity evaluated by free radical scavenging activity (DPPH).

(3) Effective concentration at $50 \%$.

(4) Total phenolic content.

(5) Antioxidant activity evaluated by the $\beta$-carotene bleaching method.

\section{CONCLUSIONS}

The use of clove as a raw material for the production of antioxidant extracts is promising due to the high quality of the present compounds. The different extraction methods used to obtain the extracts showed that the extracts obtained by ultrasound and supercritical $\mathrm{CO}_{2}$ presented higher yield when comparing with the hydro-distillation extraction. Clove extract yield reached valuesof $22 \pm 1 \%(\mathrm{w} / \mathrm{w})$ for ultrasound extraction with ethanol and $13 \pm 2 \%(\mathrm{w} / \mathrm{w})$ for ultrasound extraction with water, for supercritical extraction the yield was $12.5 \pm 0.5 \%(\mathrm{w} / \mathrm{w})$ and $3.6 \pm$ $0.6 \%(\mathrm{w} / \mathrm{w})$ for hydro-distillation.

The different methods of antioxidant activity showed the importance of supercritical extraction in obtaining bioactive extracts. The best result of the total phenolic content of the extracts was obtained by supercritical fluid extraction $(448 \pm 38 \mathrm{mg} \mathrm{GAE} / \mathrm{g})$. When the antioxidant potential was assessed by the discoloration of $\beta$-carotene/linoleic acid system, the best result was also obtained by supercritical fluid extraction $(94 \pm 4 \%)$. In tests for the determination of antioxidant potential by DPPH method, the best results of $\mathrm{EC}_{50}$ were obtained for extracts of cloves by ultrasound $(26 \mu \mathrm{g} / \mathrm{mL})$ using ethanol as solvent and hydro-distillation $(27 \mu \mathrm{g} / \mathrm{mL})$ and supercritical fluid extraction $(33 \mu \mathrm{g} / \mathrm{mL})$ with no significant difference by the Tukey's test at $95 \%$ confidence level. Therefore, supercritical extraction proved to be a technique of highlight in obtaining compounds with antioxidant activity. 


\section{REFERENCES}

ANDRADE, Maria Aparecida et al. Óleos essenciais de Cymbopogon nardus, Cinnamomum zeylanicume Zingiber officinale: composição, atividades antioxidante e Antibacteriana. Rev. C. Agro. v. 43, n. 2, 399-408. Ceará, 2012

BENELLI, P. et al. Bioactive extracts of orange (Citrus sinensis L. Osbeck) pomace obtained by SFE and low pressure techniques: Mathematical modeling and extract composition. J. of $S$. Fluids, 55, p. 132-141. Florianópolis, 2010.

CORREIA, et al. Estudo de modelos de transferência de massa para processos de extração supercrítica, Departamento de Engenharia Quimica e Engenharia de Alimentos, Universidade Federal de Santa Catarina, 2006.

FERREIRA, S. R. S.; MEIRELES, M. A. A. Modeling the supercritical fluid extraction of black pepper (Piper nigrumL.) essential oil.J. of Food Eng. v. 54, p. 263-9, 2002.

KANG, H. J. et al. Studies on the development of functional powder from citrus peel. Bio.Tech., v. 97, p. 614-20, 2006.

KITZBERGER, et al. Supercritical fluid extraction of shiitake oil: curve modeling and extract composition, J. of Food Eng. v.90, p.35-43, 2009.

MARTINEZ, J. et al. Extraction of Clove and Vetiver Oils with Supercritical Carbon Dioxide: Modeling and Simulation. The Open Chem .Eng. J. v.1, p. 1-7. Florianópolis, 2007.

MARTINEZ, J. et al. Multicomponent model to describe extraction of ginger oil in with supercritical carbon dioxide. Industrial Eng. of Chem. Research v.42, p.1057-1063, 2003.

MATTHÄUS, B. Antioxidant activity of extracts obtained from residues of different oilseeds. $J$. of Agri. and Food Chem.,v. 50(12), p. 3444-52, 2002.

MENSOR, L. L. et al. Screening of Brazilian plant extracts for antioxidant activity by the use of DPPH free radical method. Phyto.Res., v. 15, p. 127-30, 2001.

OLIVEIRA, Rosilene Aparecida et al. Constituintes químicos voláteis de especiarias ricas em eugenol. B. J.of Pharma. 19(3): 771-775. Bahia, 2009.

PESCHEL, W.F. et al. An industrial approach in the search of natural antioxidants from vegetable and fruit wastes. Food Chem. 97, p.137-150, 2006.

SCHERER, R. et al. Composição e atividades antioxidante e antimicrobiana dos óleos essenciais de cravo-da-índia, citronela e palmarosa. Rev. Bra.dePlantasMedicinais, v.11, n.4, 442-449. São Paulo, 2009. 
SINGLETON, V. L. et al. Colorimetry of total phenolics with phosphomolybdicphosphotungstic acid reagents.A. J. of Enology and Viticulture, v. 16, p. 144-58, 1965.

WENQIANG, G. et al. Comparison ofessential oils of clove buds extracted with supercritical carbon dioxide and other three traditional extraction methods Chemistry of essential oils. Food Chem., v. 101, p. 1558-1564, 2007 